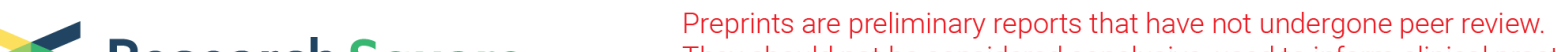

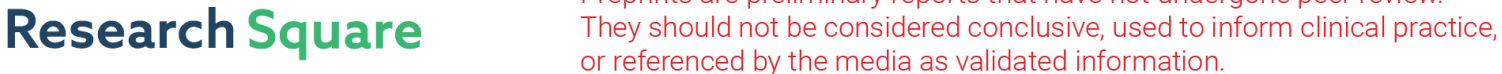

\section{Clinical Presentations and Outcomes in Transplant Patients With COVID-19: A Systematic Review and Meta-Analysis}

\section{Kirellos Abbas}

Faculty of Medicine, Alexandria University

Jaffer Shah ( $\nabla$ jaffer.shah@drexel.edu )

Drexel University College of Medicine

\section{Nahla El-Sahat}

Faculty of Medicine, Al-Azhar University

\section{Fatmaelzahraa Ali}

Faculty of Medicine, Zagazig University

\section{Esraa Mostafa}

Faculty of Medicine, Port Said University

\section{Ebrahem Khattab}

Faculty of Dental Medicine, Al-Azhar University

\section{Hadeer Sherif}

Faculty of Medicine, Cairo University

\section{Selma Klouche Djedid}

Faculty of Medicine, University of Tlemcen

\section{Yousra Elmamoun}

Faculty of Medicine and Pharmacy of Rabat, Mohammed Vth University

\section{Nada Abdhalim}

Department of Nutrition and Diatetics, School of Health Sciences, Istanbul Gelisim University

\section{Ramy Gayed}

Faculty of Medicine, Cairo University

\section{Mostafa Amin}

Faculty of Medicine, Cairo University

\section{Nitu Lama}

Dr. M. V. Shetty College of Physiotherapy, Rajiv Gandhi University of Health Sciences

\section{Majd Alahmar}

Faculty of Medicine, Mansoura University

\section{Zeinab Mohamed}

Faculty of Medicine, Aswan University

\section{Shrouk Dabbous}


Faculty of Pharmacy, Russian University

\section{Nguyen Phuong}

Faculty of Biology and Biotechnology, University of Science, Vietnam National University

\section{Ashlyn Brown}

American University of the Caribbean School of Medicine

Joseph Varney

American University of the Caribbean School of Medicine

\section{Nguyen Huy}

School of Tropical Medicine and Global Health

\section{Research Article}

Keywords: Transplant, Transplantation, Coronavirus, COVID-19, SARS-COV2

Posted Date: January 27th, 2021

DOl: https://doi.org/10.21203/rs.3.rs-132795/v1

License: (c) (1) This work is licensed under a Creative Commons Attribution 4.0 International License. Read Full License 


\section{Abstract}

Introduction: Transplant patients are a vulnerable group due to their immunocompromised status. Understanding how COVID-19 can present in this group is clinically important. Therefore, we conduct a systematic review and meta-analysis on clinical features and management of transplant patients with COVID-19.

Methods: Five databases were searched in May 2020 to include all relevant studies reporting clinical features or outcomes of COVID-19 infection in transplant patients. Data on clinical presentation, outcomes, lab values, imaging, and drug regimen were extracted. CMA software was used for metaanalysis. Protocol was registered in PROSPERO (CRD42020189458).

Results: A total of 49 studies were finally included for analysis. Patients mainly complained from fever with event rate $74.40 \%$ (95\% Cl= 69.4-78.8), cough 61.10\% (95\% Cl= 55.8-66), and dyspnea $46.60 \%$ (95\% $\mathrm{Cl}=69.4-78.8)$. Blood urea nitrogen $78.90 \%$ (95\% Cl= 54.7-92), ESR 78.10\% (95\% Cl=52.3-92.1), and Ddimer $74.10 \%$ (95 \% Cl= 53-87.9) were the most elevated observed laboratory values. Ground glass opacities (GGO) were observed with event rate $68.10 \%$ (95\% Cl= 20.4-94.9). For treatment, immunosuppressants were used in $88.80 \%(95 \% \mathrm{Cl}=77.6-94.8)$ of patients, followed by antibiotics and antiviral drugs $68.40 \%(95 \% \mathrm{Cl}=52.4-80.9), 66.80 \%(95 \% \mathrm{Cl}=45-83.2)$, respectively. Mechanical ventilation was used in $26.30 \%$ (95\% $\mathrm{Cl}=21-32.4)$ patients while $33.7 \%(95 \% \mathrm{Cl}=20.7-49.9)$ intubated. Rejection occurred in $11 \%(95 \% \mathrm{Cl}=4.4-25)$ of the patients. Finally, $18.20 \%(95 \% \mathrm{Cl}=12.6-25.7)$ died.

Conclusion: Clinical characteristics and management in transplant COVID patients suggest the similar course in non-transplant. Fever, cough, dyspnoea, elevated blood urea nitrogen level, elevated CRP, elevated d-dimer, GGO, and consolidation were found to be the most frequent abnormalities. No direct, comparative analysis with non-transplant COVID population limited our results; however, numerous studies that examined the infected general population found similar, less augmented findings. Most of the included sample were kidney transplant patients; therefore, more studies are needed to address other types of COVID-19 infected transplant patients.

\section{Introduction}

COVID-19 is considered the worst pandemic in the last 100 years. It has spread rapidly in a few months, just after its appearance in Wuhan ${ }^{1}$. Immunosuppression may be attributed to various causes; organ transplantation and glucocorticoids are prevalent causes that increase risk of infections including COVID$19^{2}$., literature on how being a transplant patient would affect its presentation, progression, and mortality is scarce. Recipients who receive solid organ transplants such as lung, heart, kidney, and liver are considered "high risk" for developing infection ${ }^{3}$. Throughout the years, improvement with graft survival and immunosuppressive agents shifted concerns of post-transplant complications towards malignancy and infection ${ }^{3,4}$. These transplant patients also are at risk for cardiovascular disease, which is the major cause of death and graft loss in diabetic renal transplant patients ${ }^{5,6}$. Hypertension and dyslipidaemia 
have been reported to be common in this population as well, both of which are major risk factors for reduced renal allograft survival and cardiovascular disease ${ }^{7,8}$. Obesity, diabetes mellitus, bone disease, and hematologic issues have all been reported as complications found in transplant recipients ${ }^{9-11}$. Comparably, most of these complications can also be found in liver, heart, and lung transplant recipients in addition to the probable complications of acute or chronic transplant rejection ${ }^{12,13}$.

Disease prevention and immunization is very important for transplant patients, but each pose their own risks to immunocompromised individuals. Lower rates of mortality have been postulated within these patients due to the blunted inflammatory response caused by immunosuppression; however, the longer the duration on immunosuppressive medications, the longer the risk of infection persists ${ }^{3}$. Therefore, epidemiologic exposures, i.e. this history of potential pathogen encounters and a patient's "net state of immunosuppression", must be adequately assessed to determine a patient's susceptibility to infection ${ }^{3}$.

The COVID-19 pandemic triggered a decline in transplantation surgeries because of fear due to complications. Additionally, the heart, lungs, and kidneys have all been shown to be involved in COVID-19, which suggests that transmission from a donor is feasible; therefore, recipients and donors need to be screened before transplantation ${ }^{14,15}$. Additionally, the management of solid organ transplant patients requires an individualized approach, particularly with the complications of COVID-19, because the reduction in immunosuppressive therapy leads to the risk of uncontrolled infection; however, without this therapy, these patients bear the risk of transplant rejection ${ }^{16,17}$.

Organ transplantation is thus considered to place patients at risk of fatal complications of COVID-19 due to the chronic use of immunosuppressive drugs (ISDs) and associated or coexisting comorbidities ${ }^{17}$. Currently, there is still limited clinical information concerning COVID-19 infected solid transplant patients, with the majority of studies reporting mainly kidney transplant patients. This systematic review and metaanalysis examined the clinical outcomes, laboratory values, CT image characteristics, and different treatment modalities for transplant patients infected with COVID-19.

\section{Methods}

\section{Protocol registration}

This systematic review was performed following the 2009 Preferred Reporting Items for Systematic Reviews and Meta-Analyses (PRISMA) guidelines ${ }^{18,19}$. Detailed steps are described in Supplementary Table 1. A prior protocol of methods has been developed and registered with the international prospective register of systematic reviews (PROSPERO) with ID number CRD42020189458 on June $3^{\text {rd }}, 2020$.

\section{Search strategy}

We developed a search strategy to obtain all original studies reporting clinical data of transplant patients infected with COVID-19. On May $27^{\text {th }}, 2020$, we searched five electronic databases: PubMed, Web of 
Science (ISI), Scopus, BioRexiv and MedRexiv using the following search term: (transplant OR transplantation OR graft) AND (recipient OR recipients OR donor OR donors OR donor) AND (SARS OR coronavirus OR nCoV OR "Cov-2" OR Cov2 OR COVID). Our search was restricted from $1^{\text {st }}$ January 2020. Additional manual searches were also performed by screening references of our included studies and searching PubMed/Google Scholar for related or similar articles. More details for the search in each database and modifications on the search terms can be found in Supplementary Table 2.

\section{Selection criteria}

Any relevant study that reported the clinical features or outcomes of COVID-19 infection in transplantation patients were included with no restriction regarding location, gender, age, race, language, or ethnicity were included. We excluded correspondence, book chapters, abstract-only articles, conference papers, reviews, theses, posters, author responses, editorials, letters, non-extractable data, duplications, unreliable data sets, overlapping, and in vitro and animal studies.

\section{Study selection}

Covidence was used as a semiautomated program to conduct title/abstract screening after duplicates were removed ${ }^{20}$. Three independent reviewers screened full texts. Any disagreement between reviewers was resolved through discussion and consensus. If disagreement was still not resolved, a senior researcher was consulted and made the final decision.

\section{Data extraction}

Data from each study were extracted by three independent reviewers into a spreadsheet that included the following information: study characteristics such as title, first author name, publication year, country of the publication, study design, sample size, journal name; patients characteristics such as gender, age category, type of transplantation, comorbidities, and follow up duration; and outcomes such as event numbers for common signs and symptoms, vital sign categories (above normal, below normal, normal), common radiological findings, laboratory value categories (below normal, normal, elevated), positive swabs results for COVID-19 detection, hospitalization, ICU admission, mechanical ventilation, intubation, death, recovery and rejection, treatments used in terms of antivirals, antibiotics, hydroxychloroquine, immunoglobulin, anticoagulants, and steroids. Any disagreement was resolved through discussion and consensus.

\section{Quality assessment and risk of bias}

Three independent reviewers assessed quality and bias using the NIH tool for cohort, cross sectional, and case series studies. The Joanna Briggs Institute Critical Appraisal Checklist Tool was used for case reports ${ }^{21,22}$. Any disagreement was resolved with discussion and consensus. Scoring was one point for "YES", zero points for "NO", "cannot determine (CD)" or "not applicable (NA)". The following grading categories and score ranges were used: good, fair, and poor. In case reports: good (7-8), fair (4-6), poor (1- 
3). In case series: good (7-9), fair (4-6), poor (1-3). For cross sectional studies and cohort studies: good (9-14), fair (5-8), poor (1-4).

\section{Statistical analysis and results interpretation}

Event rates and their $95 \%$ confidence intervals $(\mathrm{Cl})$, calculated by dividing the number of events by the number of all patients, were computed for signs, symptoms, treatments, outcomes. Subgroups based on transplantation type were formed and calculated according to available data. Studies less than or equal to 5 patients were pooled together and named as a single dataset. We used the Comprehensive Metaanalysis software (CMA) version 3.3.07 for meta-analysis (Biostat, NJ, USA). We considered heterogeneity significant if the inconsistency $\left(\mathrm{I}^{2}\right)$ of effect estimates $>50 \%$ or $p$-value 0.1 across studies ${ }^{20}$. If heterogeneity was statistically significant, we used a fixed-effects model; if not, a random-effects model was used.

\section{Results}

\section{Systematic search and its results}

A total of 446 articles were initially included from PubMed, Scopus, Web of Science, and MedRxiv databases. After removing duplicates, a total of 333 studies went through title and abstract screening. 218 articles were excluded according to exclusion criteria, leaving 115 articles for full-text screening. 46 were irrelevant to our topic, 24 non-original, Eleven contain non-extractable data and only one nonavailable full text. 16 articles were included from manual searches. A total of 49 articles were finally included 16,23-29,41-45,47-55,57-61,63-82. All studies involved in our analysis. 33 studies were combined as a single case dataset with five cases or less while 16 studies were involved as them. Detailed steps are described in Figure 1.

\section{Studies and participants' characteristics}

Of the 49 included articles, 24 were case reports, 17 were case series, 2 were retrospective studies, 2 were cohort studies, and 4 were cross-sectional studies. 16 studies were conducted in the United States, 8 in Italy, 14 in China, 2 in Iran, 1 in Switzerland, 1 in Turkey, 1 in Korea, 1 in the Netherlands, 2 in Spain, 1 in the United Kingdom, 1 in Brazil, and 1 in Germany. Our systematic review and meta-analysis represent a total of 381 transplant patients who were infected with COVID-19. The types of transplants included liver, kidney, bone marrow, pancreas, heart, and single and bilateral lung. There was a total number of 280 males and 101 females that were represented across all studies. The age of the study subjects ranged from 13 to 80 years. The characteristics table is fully represented in Supplementary Table 3.

\section{Quality Assessment}

The NIH tool was used to evaluate the quality of the included studies. 42 studies showed "good" quality, 7 studies showed "fair" quality, and no studies showed "poor" quality. More details on the results of each 
study are found in Supplementary Table 3.

\section{Synthesis of results}

Data for 381 patients were meta-analysed for pooled event rate of clinical signs and symptoms (Figure 2), laboratory values (Figure 3), imaging features (Figure 4), and treatment modalities (Figure 5), patient outcomes (Figure 6). Detailed data analysis results with single data set removal analysis and subgroup analysis according to the type of transplantation depending on the available data can be found in the

\section{Supplementary Table 4.}

\section{Clinical signs and symptoms}

Figure 2 summarizes the meta-analysis for clinical signs and symptoms. Fever and cough had the highest event rates of $74.4 \%(95 \% \mathrm{Cl}=69.4-78.8)$ and $61.1 \%(95 \% \mathrm{Cl}=55.8-66)$, respectively, while asymptomatic had the lowest event rate $11.30 \%$ (95\% $\mathrm{Cl}=3.3-32.5)$. After fever and cough, the next symptom that occurred most frequently was dyspnea, which had a $46.6 \%$ event rate $(95 \% \mathrm{Cl}=37.2-56.3)$. Other symptoms that occurred had a lower event rate, with more details found in Figure 2 and

\section{Supplementary Table 4.}

\section{Laboratory investigations}

The laboratory findings in our study are shown in Figure 3. Elevated blood urea nitrogen level was the most observed at $78.90 \%(95 \% \mathrm{Cl}=54.7-92)$, followed by an elevated $\mathrm{ESR}$ at $78.10 \%(95 \% \mathrm{Cl}=52.3-92.1)$ and an elevated D-dimer at $74.10 \%(95 \% \mathrm{Cl}=53-87.9 \%)$. More details can be seen in Supplementary Table 4.

\section{Imaging features}

The events rates for the radiological findings are found in Figure 4. The most observed feature was ground glass opacity at $68.1 \%(95 \% \mathrm{Cl}=0.20 .4-94.9)$, followed by consolidation at $58.4 \%(95 \% \mathrm{Cl}=33.3-$ $79.8)$ and patchy shadows at $37 \%(95 \% \mathrm{Cl}=0.5 .8-84.8)$. Dilated small vessels was shown in $21.8 \%(95 \%$ $\mathrm{Cl}=0.2-97.5)$ and interlobular septal thickening had the lowest event rate at $12.8 \%(95 \% \mathrm{Cl}=0.4-83.4)$. More details can be seen in Supplementary Table 4.

\section{Treatment modalities}

Figure 5 summarizes the event rates of different medications given to COVID-19 transplant patients. The most used treatment was immunosuppressants at $88.8 \%(95 \% \mathrm{Cl}=77.6-94.8)$, with antibiotics at $68.4 \%$ (9\% $\mathrm{Cl}=52.4-80.9)$ and anti-virals at $66.8 \%$ (95\% Cl= 45-83.2). Immunoglobulin and hydroxychloroquine's event rate followed at $65.1 \%(95 \% \mathrm{Cl}=30.2-88.9)$ and $65.0 \%(95 \% \mathrm{Cl}=50.1-77.5)$, respectively. Notably, the event rate for anticoagulants was $44.9 \%(95 \% \mathrm{Cl}=18.2-74.9)$. Other event rates for other types of drugs and details can be found further in Supplementary Table 4.

\section{Patient clinical outcomes}


The events rates of clinical outcomes for all COVID-19 infected transplant patients can be found in Figure 6. $77.1 \%(95 \% \mathrm{Cl}=72-81.6)$ of patients hospitalized, $26.30 \%(95 \% \mathrm{Cl}=21-32.4)$ mechanically ventilated and $33.7 \%$ (95\% Cl= 20.7-49.9) intubated. Death event rate was 18.20\% (95\% Cl=12.6-25.7) Transplant rejection occurred in four patients at 11\% (95\% Cl=4.4-25). Detailed data represented in Supplementary

Table 4.

\section{Discussion}

Transplant patients face many health challenges and require careful monitoring for drug side effects and possible infections due to the immunosuppressive drugs they need to prevent organ rejection ${ }^{17}$. Our systematic review and meta-analysis provided evidence for the clinical outcomes, laboratory values, diagnostic imaging, and various treatment modalities used amongst transplant patients diagnosed with COVID-19.

Regarding the clinical outcomes, our findings revealed that fever (74.4\%) and cough (61.1\%) are the most frequently encountered symptoms. A meta-analysis done by Li et al. focused on the general populace in 1995 COVID-19 cases. The most common symptoms encountered in this meta-analysis were fever (88.5\%) and cough (68.6\%), which matches the same clinical profile of our meta-analysis ${ }^{69}$. The values may have slight variation due to the number of studies included in each meta-analysis; however, both studies can attest to fever and cough being the most encountered symptoms. Additionally, we found that diarrhea and dyspnea occur frequently with an event rate of $31.2 \%$ and $46.6 \%$, respectively. The metaanalysis done by Li et. al. showed diarrhea to be a minor symptoms with an event rate of $4.8 \%$ and dyspnea to be considered a main clinical symptom with an event rate of $21.9 \%{ }^{69}$. Although diarrhea could be a side effect of COVID-19, the high event rate of diarrhea from our meta-analysis could be due to the side effects of medications and polypharmacy instead of COVID-19, since post-transplant patients, compared to the general populace, commonly experience diarrhea as a symptom ${ }^{70}$. Expectoration (sputum production) occurs rarely with an event rate of $2.3 \%$ in our meta-analysis. Compared to the general population with an expectoration event rate of $28.2 \%$, our findings were reduced ${ }^{69}$. We did not expect expectoration to be an infrequent symptom, as it seems to be common in the general populace ${ }^{71}$.

The connection between the kidney and the lung is well established. Since most of our study involves kidney transplant patients with a single working kidney, dysfunction in that single kidney may cause these patients to be more susceptible to acidosis during an infection, leading to hyperventilation and dyspnoea as respiratory compensation ${ }^{71,72}$. In our meta-analysis, intubation event rate was found to be $33.7 \%$. A systematic review and meta-analysis showed the crude prevalence of invasive mechanical ventilation in the COVID-19 general populace to be $6.79 \%$. When compared to our population, intubation rate is significantly higher at a $26.9 \%$ difference, which supports our findings of greater respiratory distress in transplant patients ${ }^{73}$. Another consideration should be the similarity of symptoms between COVID-19 and influenza within vulnerable populations. Both viruses have been shown to present with similar symptoms like fever, diarrhoea, myalgia, malaise, and dyspnoea. The initial outbreak of COVID-19 
occurred during a period where there were high rates of respiratory viruses such as respiratory syncytial virus, influenza, and many others. Vaccines such as the influenza vaccine are useful in reducing the confusion between symptoms caused by COVID-19 and other similar respiratory viruses ${ }^{74}$. Obtaining knowledge of the vaccination history as well as prior infection history of our patients in our study may help better explain some of our findings ${ }^{25}$. Obtaining prior knowledge is particularly important since the aforementioned respiratory viruses, in addition to the respiratory syncytial virus, parainfluenza virus, and rhinovirus, are becoming more recognized as major causes of respiratory illnesses in patients after receiving a single organ transplant ${ }^{26}$.

Additionally, comorbid conditions like diabetes and heart failure in transplant patients are common and may further complicate the COVID-19 infection. For instance, in a study that assessed comorbid conditions in kidney transplant patients, diabetes was found in $30.3 \%$ of patients and heart failure was found in $11.9 \%{ }^{74}$. Another study that explored comorbid conditions in lung transplant patients showed that, out of 223 people, $19.7 \%$ had diabetes and $9 \%$ had heart failure. These conditions seem to be common in transplant patients, compared to the $9.7 \%$ who had diabetes and $8.4 \%$ who had cardiovascular disease as seen in a systematic review and meta-analysis reviewing commodities in the general COVID-19 infected population; therefore, increased prevalence of certain comorbidities could also affect the clinical outcome of transplant patients ${ }^{25,29}$.

Regarding the laboratory values found within our meta-analysis, abnormalities were typical for all patients hospitalized with COVID-19 and not just transplant patients. Liver injury secondary to COVID-19, like prolonged prothrombin time, elevated aminotransferases, and hypoproteinemia, have been reported by numerous studies and are thought to be due to direct liver damage from the virus itself, drug hepatotoxicity, and immune-mediated inflammation ${ }^{26}$. COVID-19 is associated with immunosuppression, causing a depression in CD4+ and CD8+ lymphocytes and leading to lymphopenia. Elevated ESR, CRP, and D-Dimer reflect an inflammatory state typical of a COVID-19 infection, with an increase of LDH reflecting systematic damage in the body ${ }^{23}$. There is a parallel response in the inflammatory mediators in COVID-19 and the disease severity. The laboratory findings in our meta-analysis show that $59.3 \%$ of our patients had elevated IL- 6 markers. IL- 6 is an interleukin that stimulates acute phase responses, immune reactions, and haematopoiesis as a response to tissue injury and infections. An increasing rise in this marker may be an indication of the severity of COVID-1923. According to the case report done by Hammami et al., the timing of the administration of particular immunosuppressive therapy may help reverse the progression from mild to severe inflammatory response associated with COVID-1923.

In reference to the diagnostic imaging reported by our meta-analysis, our study showed that consolidation had an event rate of $58.4 \%$ and was the $2^{\text {nd }}$ most frequent characteristic. When compared to a systematic review of different imaging features in 919 COVID-19 patients, only 10 studies reported consolidation; thus, demonstrating the lease percentage of cases at $31.8^{75}$. Other than this discrepancy, our findings generally agree that COVID-19 images for transplant patients are often bilateral with consolidation and ground glass opacity, with pleural effusion being the least prevalent feature ${ }^{24}$. The 
severity of COVID-19 is believed to primarily be influenced by the inflammatory response that was discussed previously. Patients who present with COVID-19 pneumonia with progression to acute respiratory distress syndrome therefore have a higher inflammation-related index. The consolidation and characteristic pleural effusion represent the pulmonary inflammatory response caused by the elevated IL6 in the blood ${ }^{23}$.

We found that $11 \%$ of the total patients in our study experienced transplant rejection. Rejection varied from minimal cellular rejection to acute organ rejection and deterioration in donor organ function. According to the data available, there is no exact relationship between change in the regimen of treatment and rejection, although it was reported that respiratory viral infection may lead to rejection ${ }^{28}$. Acute organ rejection was witnessed in four patients; however, the rejections occurred before COVID-19 infection, which suggests that acute rejection secondary to COVID-19 is likely a minimal feature ${ }^{26}$.

We found the death rate of COVID-19 transplant patients to be $18.2 \%$. In a meta-analysis and systematic review done by Jutzeler et. a/ which measured COVID-19 in the general population, the death rate was $7.97 \%{ }^{73}$. The death rate found in the transplant patients within our meta-analysis is almost double this value. This does not come as a surprise when analysing potential causes of death in solid organ transplant patients infected with COVID-19 within similar studies. Our findings agree with the 2007 study done by Fishman et.al. which found that transplant patients using immunosuppressants are susceptible to serious infection and other complications ${ }^{3}$. However, our meta-analysis shows that most patients were not put on anti-coagulation, which had an event ratio of $44.9 \%$. Our analysis did not include causes of death; however, we can surmise from the anti-coagulation event rate that lack of anticoagulation could have elevated the fatality rate due to complications arising from venous thromboembolism for all types of COVID-19 infected transplant patients. According to Ahmed et al., targeting COVID-19 without reducing the risk for thrombosis is rudimentary, since the formation of microthrombi is common in these patients. These microthrombi have been shown to form in the lung vasculature and alter lung perfusion, thus leading to hypoxemia that can ultimately lead to death ${ }^{76,77}$.

Finally, in reference to various treatment methods presented in our meta-analysis, the most common treatment found in organ transplant patients diagnosed with COVID-19 are immunosuppressants $23,24,27$. Jutzeler et al. corticosteroids are commonly administered to hospitalized patients with severe disease despite the controversy of their benefit ${ }^{73}$. From the studies included, hydroxychloroquine was the second most frequently administered drug, followed by antibiotics and antivirals ${ }^{78}$. According to In our metaanalysis, we observed high percentages of withdrawal or decrease in dosage of such immunosuppressant drugs, with kidney transplant patients having the highest event rates of withdrawal at $63 \%$ and liver transplant patients with the highest event rates of dosage decrease at $75.0 \%$. It is possible that patients began experiencing side-effects of immunosuppressive therapy or acquired comorbidities such as hypertension, kidney failure, chronic myelosuppression, or others, which may explain the high event rates ${ }^{27}$. Another possible explanation is that patients began to improve to a point that did not warrant the dosages of immunosuppressant drugs that were initially prescribed. 


\section{Limitations}

Our meta-analysis did not analyse the clinical complications in each study, such as myocarditis, arrhythmias, heart attacks, strokes, or bacterial co-infection. The number of lung transplant, heart transplant, and liver transplant patients infected by COVID-19 is limited in this study, as most patients in this study are kidney transplant patients. Therefore, the results from the meta-analysis must be taken carefully for non-kidney transplant patients. This study did not meta-analyse the difference between transplant and non-transplant patients. Most of the included studies are case reports/series with short follow up. This increases the need for a randomized control trial comparing the outcomes between the two populations.

\section{Conclusion}

In conclusion, fever, cough, dyspnoea, elevated blood urea nitrogen level, elevated CRP, elevated d-dimer, GGO, and consolidation are the most prevalent abnormalities in transplant patients with COVID-19. These abnormalities are augmented in transplant patients; however, they can also be found within the general population. Since kidney transplant patients represented most of the included sample, more studies are needed to address other types of COVID-19 infected transplant patients, the efficacy of different treatment modalities, and longer follow up periods.

\section{Declarations}

- Ethics approval and consent to participate - Not applicable for Systematic Review

- Consent for publication - Yes all authors consent to publication and have seen this final version of the manuscript

\section{Data Availability Statement}

All data generated or analysed during this study are included in this published article [and its supplementary information files].

Availability of data and materials: Available to Publish, not published before

\section{Acknowledgment}

None

\section{Funding}

None

\section{Conflict of interest/Competing Interests}


The authors had no conflict of interest to conduct this study

\section{Author Contributions}

JS was responsible for the idea under supervision of NTH. KSA, NA, FEY and EMK organized tasks, made tables and figures under supervision of NTH. Data analysis was done by KSA, NA and HAS. EMM revised it. All authors KSA, JSA, NA, FEY, EMM, EMK, HAS, YEE, NKA, RMG, MAA, NL, MA, ZAM, SAD, SNKD, NQP, $A B, J V, N T H$ contributed to the manuscript writing, manuscript proofreading, revision and approval of the final version.

\section{References}

1. Tang Y, Wang S. Mathematic modeling of COVID-19 in the United States. Emerg Microbes Infect. 2020;9(1):827-829. doi:10.1080/22221751.2020.1760146

2. McGrath B, Broadhurst $M$, Roman $C$. Infectious disease considerations in immunocompromised patients. Journal of the American Academy of PAs. 2020;33(9):16-25.

doi:10.1097/01.JAA.0000694948.01963.f4

3. Fishman JA. Infection in solid-organ transplant recipients. N Engl J Med. 2007;357(25):2601-2614. doi:10.1056/NEJMra064928

4. Fishman JA, Issa NC. Infection in organ transplantation: risk factors and evolving patterns of infection. Infect Dis Clin North Am. 2010;24(2):273-283. doi:10.1016/j.idc.2010.01.005

5. Kasiske BL, Guijarro C, Massy ZA, Wiederkehr MR, Ma JZ. Cardiovascular disease after renal transplantation. J Am Soc Nephrol. 1996;7(1):158-165.

6. Aakhus S, Dahl K, Wideroe T. Cardiovascular morbidity and mortality in renal transplant recipients. Nephrol Dial Transplant. 1997;12:A158.

7. Kasiske BL, Anjum S, Shah R, et al. Hypertension after kidney transplantation. Am J Kidney Dis. 2004;43(6):1071-1081. doi:10.1053/j.ajkd.2004.03.013

8. Gotti E, Perico N, Perna A, et al. Renal Transplantation: Can We Reduce Calcineurin Inhibitor/Stop Steroids? Evidence Based on Protocol Biopsy Findings. JASN. 2003;14(3):755-766. doi:10.1097/01.ASN.0000048717.97169.29

9. Gore JL, Pham PT, Danovitch GM, et al. Obesity and outcome following renal transplantation. Am J Transplant. 2006;6(2):357-363. doi:10.1111/j.1600-6143.2005.01198.x

10. Snyder RW, Berns JS. Use of insulin and oral hypoglycemic medications in patients with diabetes mellitus and advanced kidney disease. Semin Dial. 2004;17(5):365-370. doi:10.1111/j.08940959.2004.17346.x

11. Hartmann EL, Gatesman M, Roskopf-Somerville J, Stratta R, Farney A, Sundberg A. Management of leukopenia in kidney and pancreas transplant recipients. Clin Transplant. 2008;22(6):822-828. doi:10.1111/j.1399-0012.2008.00893.x 
12. Torbenson M, Wang J, Nichols L, Jain A, Fung J, Nalesnik MA. Causes of death in autopsied liver transplantation patients. Mod Pathol. 1998;11(1):37-46.

13. Magro CM, Deng A, Pope-Harman A, et al. Humorally mediated posttransplantation septal capillary injury syndrome as a common form of pulmonary allograft rejection: a hypothesis. Transplantation. 2002;74(9):1273-1280. doi:10.1097/00007890-200211150-00013

14. 1COVID19 FAQ Tx Centers 04.15.2020.pdf. Accessed November 29, 2020. https://www.myast.org/sites/default/files/1COVID19\%20FAQ\%20Tx\%20Centers\%2004.15.2020.pdf

15. SARS-CoV-2_Guidance-for-Cardiothoracic-Transplant-and-VAD-centers.pdf. Accessed November 29, 2020. https://ishlt.org/ishlt/media/documents/SARS-CoV-2_Guidance-for-Cardiothoracic-Transplantand-VAD-centers.pdf

16. Pereira MR, Mohan S, Cohen DJ, et al. COVID-19 in solid organ transplant recipients: Initial report from the US epicenter. American Journal of Transplantation. 2020;20(7):1800-1808. doi:https://doi.org/10.1111/ajt.15941

17. de Vries APJ, Alwayn IPJ, Hoek RAS, et al. Immediate impact of COVID-19 on transplant activity in the Netherlands. Transpl Immunol. 2020;61:101304. doi:10.1016/j.trim.2020.101304

18. Liberati A, Altman DG, Tetzlaff $\mathrm{J}$, et al. The PRISMA statement for reporting systematic reviews and meta-analyses of studies that evaluate healthcare interventions: explanation and elaboration. $B M J$. 2009;339. doi:10.1136/bmj.b2700

19. Tawfik GM, Dila KAS, Mohamed MYF, et al. A step by step guide for conducting a systematic review and meta-analysis with simulation data. Tropical Medicine and Health. 2019;47(1):46. doi:10.1186/s41182-019-0165-6

20. Covidence - Better systematic review management. Covidence. Accessed November 29, 2020. https://www.covidence.org/

21. Study Quality Assessment Tools | NHLBI, NIH. Accessed November 29, 2020. https://www.nhlbi.nih.gov/health-topics/study-quality-assessment-tools? fbclid=IwAR2RZnsyhisSbhN_PSBuKrlzqLH0X2Sb6cCluSa9Y5prBWN29TDsmsjjpIM

22. Moola S, Munn Z, Tufanaru C, et al. Chapter 7: Systematic Reviews of Etiology and Risk. In: Aromataris E, Munn Z, eds. JBI Manual for Evidence Synthesis. JBI; 2020. doi:10.46658/JBIMES-2008

23. Hammami MB, Garibaldi B, Shah P, et al. Clinical course of COVID-19 in a liver transplant recipient on hemodialysis and response to tocilizumab therapy: A case report. Am J Transplant. 2020;20(8):22542259. doi:10.1111/ajt.15985

24. Fontana F, Alfano G, Mori G, et al. COVID-19 pneumonia in a kidney transplant recipient successfully treated with tocilizumab and hydroxychloroquine. Am J Transplant. 2020;20(7):1902-1906. doi:10.1111/ajt.15935

25. Kumar D, Erdman D, Keshavjee S, et al. Clinical impact of community-acquired respiratory viruses on bronchiolitis obliterans after lung transplant. Am J Transplant. 2005;5(8):2031-2036. doi:10.1111/j.1600-6143.2005.00971.x 
26. Hong H-L, Kim S-H, Choi DL, Kwon HH. A case of coronavirus disease 2019-infected liver transplant donor. American Journal of Transplantation. 2020;20(10):2938-2941.

doi:https://doi.org/10.1111/ajt.15997

27. Koczulla RA, Sczepanski B, Koteczki A, et al. SARS-CoV-2 infection in two patients following recent lung transplantation. Am J Transplant. 2020;20(10):2928-2932. doi:10.1111/ajt.15998

28. Kates OS, Fisher CE, Stankiewicz-Karita HC, et al. Earliest cases of coronavirus disease 2019 (COVID19) identified in solid organ transplant recipients in the United States. Am J Transplant. 2020;20(7):1885-1890. doi:10.1111/ajt.15944

29. Lee BT, Perumalswami PV, Im GY, Florman S, Schiano TD. COVID-19 in Liver Transplant Recipients: An Initial Experience From the US Epicenter. Gastroenterology. 2020;159(3):1176-1178.e2. doi:10.1053/j.gastro.2020.05.050

30. Hoek RAS, Manintveld OC, Betjes MGH, et al. COVID-19 in solid organ transplant recipients: a singlecenter experience. Transplant International. 2020;33(9):1099-1105. doi:https://doi.org/10.1111/tri.13662

31. Chen J-Y, Qiao K, Liu F, et al. Lung transplantation as therapeutic option in acute respiratory distress syndrome for coronavirus disease 2019-related pulmonary fibrosis. Chin Med J (Engl). 2020;133(12):1390-1396. doi:10.1097/CM9.0000000000000839

32. Hsu JJ, Gaynor P, Kamath M, et al. COVID-19 in a high-risk dual heart and kidney transplant recipient. Am J Transplant. 2020;20(7):1911-1915. doi:10.1111/ajt.15936

33. Lagana SM, De Michele S, Lee MJ, et al. COVID-19 Associated Hepatitis Complicating Recent Living Donor Liver Transplantation. Arch Pathol Lab Med. Published online April 17, 2020. doi:10.5858/arpa.2020-0186-SA

34. Latif F, Farr MA, Clerkin KJ, et al. Characteristics and Outcomes of Recipients of Heart Transplant With Coronavirus Disease 2019. JAMA Cardiol. Published online May 13, 2020. doi:10.1001/jamacardio.2020.2159

35. Bussalino E, De Maria A, Russo R, Paoletti E. Immunosuppressive therapy maintenance in a kidney transplant recipient with SARS-CoV-2 pneumonia: A case report. Am J Transplant. 2020;20(7):19221924. doi:10.1111/ajt.15920

36. Alberici F, Delbarba E, Manenti C, et al. A single center observational study of the clinical characteristics and short-term outcome of 20 kidney transplant patients admitted for SARS-CoV2 pneumonia. Kidney Int. 2020;97(6):1083-1088. doi:10.1016/j.kint.2020.04.002

37. Abrishami A, Samavat S, Behnam B, Arab-Ahmadi M, Nafar M, Sanei Taheri M. Clinical Course, Imaging Features, and Outcomes of COVID-19 in Kidney Transplant Recipients. Eur Urol. 2020;78(2):281-286. doi:10.1016/j.eururo.2020.04.064

38. Zhong Z, Zhang $\mathrm{Q}$, Xia $\mathrm{H}$, et al. Clinical characteristics and immunosuppressant management of coronavirus disease 2019 in solid organ transplant recipients. Am J Transplant. 2020;20(7):19161921. doi:10.1111/ajt.15928 
39. Zhang H, Chen Y, Yuan Q, et al. Identification of Kidney Transplant Recipients with Coronavirus Disease 2019. European Urology. 2020;77(6):742-747. doi:10.1016/j.eururo.2020.03.030

40. Huang J, Lin H, Wu Y, et al. COVID-19 in posttransplant patients-report of 2 cases. Am J Transplant. 2020;20(7):1879-1881. doi:10.1111/ajt.15896

41. Tschopp J, L'Huillier AG, Mombelli M, et al. First experience of SARS-CoV-2 infections in solid organ transplant recipients in the Swiss Transplant Cohort Study. Am J Transplant. 2020;20(10):28762882. doi:10.1111/ajt.16062

42. Ning L, Liu L, Li W, et al. Novel coronavirus (SARS-CoV-2) infection in a renal transplant recipient: Case report. Am J Transplant. 2020;20(7):1864-1868. doi:10.1111/ajt.15897

43. Machado DJ de B, lanhez LE. COVID-19 pneumonia in kidney transplant recipients-Where we are? Transp/ Infect Dis. Published online May 4, 2020:e13306. doi:10.1111/tid.13306

44. Zhu L, Gong N, Liu B, et al. Coronavirus Disease 2019 Pneumonia in Immunosuppressed Renal Transplant Recipients: A Summary of 10 Confirmed Cases in Wuhan, China. Eur Urol. 2020;77(6):748-754. doi:10.1016/j.eururo.2020.03.039

45. Zhu L, Xu X, Ma K, et al. Successful recovery of COVID-19 pneumonia in a renal transplant recipient with long-term immunosuppression. Am J Transplant. 2020;20(7):1859-1863. doi:10.1111/ajt.15869

46. Qin J, Wang H, Qin X, et al. Perioperative Presentation of COVID-19 Disease in a Liver Transplant Recipient. Hepatology. Published online March 27, 2020. doi:10.1002/hep.31257

47. Liu B, Wang Y, Zhao Y, Shi H, Zeng F, Chen Z. Successful treatment of severe COVID-19 pneumonia in a liver transplant recipient. Am J Transplant. 2020;20(7):1891-1895. doi:10.1111/ajt.15901

48. Fernández-Ruiz M, Andrés A, Loinaz C, et al. COVID-19 in solid organ transplant recipients: A singlecenter case series from Spain. Am J Transplant. 2020;20(7):1849-1858. doi:10.1111/ajt.15929

49. Donato MF, Invernizzi F, Lampertico P, Rossi G. Health Status of Patients Who Underwent Liver Transplantation During the Coronavirus Outbreak at a Large Center in Milan, Italy. Clin Gastroenterol Hepatol. 2020;18(9):2131-2133.e1. doi:10.1016/j.cgh.2020.04.041

50. Bush R, Johns F, Acharya R, Upadhyay K. Mild COVID-19 in a pediatric renal transplant recipient. Am J Transplant. 2020;20(10):2942-2945. doi:10.1111/ajt.16003

51. Namazee N, Mahmoudi H, Afzal P, Ghaffari S. Novel Corona Virus 2019 pneumonia in a kidney transplant recipient. Am J Transplant. Published online May 13, 2020. doi:10.1111/ajt.15999

52. Guillen E, Pineiro GJ, Revuelta I, et al. Case report of COVID-19 in a kidney transplant recipient: Does immunosuppression alter the clinical presentation? American Journal of Transplantation. 2020;20(7):1875-1878. doi:https://doi.org/10.1111/ajt.15874

53. Cozzi E, Faccioli E, Marinello S, et al. COVID-19 pneumonia in lung transplant recipients: Report of 2 cases. American Journal of Transplantation. 2020;20(10):2933-2937. doi:https://doi.org/10.1111/ajt.15993

54. Chenna A, Konala VM, Gayam V, Naramala S, Adapa S. Coronavirus Disease 2019 (COVID-19) in a Renal Transplant Patient. Cureus. 12(5). doi:10.7759/cureus.8038 
55. Cheng D, Wen J, Liu Z, Lv T, Chen J. Coronavirus disease 2019 in renal transplant recipients: Report of two cases. Transplant Infectious Disease. 2020;22(5):e13329.

doi:https://doi.org/10.1111/tid.13329

56. Bartiromo M, Borchi B, Botta A, et al. Threatening drug-drug interaction in a kidney transplant patient with coronavirus disease 2019 (COVID-19). Transpl Infect Dis. 2020;22(4):e13286. doi:10.1111/tid.13286

57. Arpali E, Akyollu B, Yelken B, Tekin S, Turkmen A, Kocak B. Case report: A kidney transplant patient with mild COVID-19. Transp/ Infect Dis. 2020;22(4):e13296. doi:10.1111/tid.13296

58. Fung M, Chiu CY, DeVoe $C$, et al. Clinical outcomes and serologic response in solid organ transplant recipients with COVID-19: A case series from the United States. Am J Transplant. Published online June 1, 2020. doi:10.1111/ajt.16079

59. Akalin E, Azzi Y, Bartash R, et al. Covid-19 and Kidney Transplantation. N Engl J Med. 2020;382(25):2475-2477. doi:10.1056/NEJMc2011117

60. Wang J, Li X, Cao G, Wu X, Wang Z, Yan T. COVID-19 in a Kidney Transplant Patient. Eur Urol. 2020;77(6):769-770. doi:10.1016/j.eururo.2020.03.036

61. Holzhauser L, Lourenco L, Sarswat N, Kim G, Chung B, Nguyen AB. Early experience of COVID-19 in 2 heart transplant recipients: Case reports and review of treatment options. Am J Transplant. 2020;20(10):2916-2922. doi:10.1111/ajt.15982

62. Meziyerh S, Zwart TC, van Etten RW, et al. Severe COVID-19 in a renal transplant recipient: A focus on pharmacokinetics. Am J Transplant. 2020;20(7):1896-1901. doi:10.1111/ajt.15943

63. Verma A, Khorsandi SE, Dolcet A, et al. Low prevalence and disease severity of COVID-19 in post-liver transplant recipients-A single centre experience. Liver International. 2020;40(8):1972-1976. doi:https://doi.org/10.1111/liv.14552

64. Yi SG, Rogers AW, Saharia A, et al. Early Experience With COVID-19 and Solid Organ Transplantation at a US High-volume Transplant Center. Transplantation. Published online June 16, 2020. doi:10.1097/TP.0000000000003339

65. Xu JJ, Samaha D, Mondhe S, Massicotte-Azarniouch D, Knoll G, Ruzicka M. Renal Infarct in a COVID19 Positive Kidney-Pancreas Transplant Recipient. Am J Transplant. Published online June 1, 2020. doi:10.1111/ajt.16089

66. Keller BC, Le A, Sobhanie M, et al. Early COVID-19 infection after lung transplantation. Am J Transplant. Published online June 11, 2020. doi:10.1111/ajt.16097

67. Lubetzky M, Aull M, Craig-Shapiro R, et al. Kidney Allograft Recipients Diagnosed with Coronavirus Disease-2019: A Single Center Report. medRxiv. Published online May 8, 2020:2020.04.30.20086462. doi:10.1101/2020.04.30.20086462

68. Cavagna L, Bruno R, Zanframundo G, et al. Clinical presentation and evolution of COVID-19 in immunosuppressed patients. Preliminary evaluation in a North Italian cohort on calcineurin-inhibitors based therapy. medRxiv. Published online May 1, 2020:2020.04.26.20080663. doi:10.1101/2020.04.26.20080663 
69. Li L-Q, Huang T, Wang Y-Q, et al. COVID-19 patients' clinical characteristics, discharge rate, and fatality rate of meta-analysis. J Med Virol. 2020;92(6):577-583. doi:10.1002/jmv.25757

70. Pant C, Deshpande A, Larson A, O'Connor J, Rolston DDK, Sferra TJ. Diarrhea in solid-organ transplant recipients: a review of the evidence. Current Medical Research and Opinion. 2013;29(10):1315-1328. doi:10.1185/03007995.2013.816278

71. Nagami GT, Hamm LL. Regulation of Acid-Base Balance in Chronic Kidney Disease. Adv Chronic Kidney Dis. 2017;24(5):274-279. doi:10.1053/j.ackd.2017.07.004

72. Wu C, Evans I, Joseph R, et al. Comorbid conditions in kidney transplantation: association with graft and patient survival. J Am Soc Nephrol. 2005;16(11):3437-3444. doi:10.1681/ASN.2005040439

73. Cr J, L B, Cv W, et al. Comorbidities, clinical signs and symptoms, laboratory findings, imaging features, treatment strategies, and outcomes in adult and pediatric patients with COVID-19: A systematic review and meta-analysis. Travel Med Infect Dis. 2020;37:101825-101825. doi:10.1016/j.tmaid.2020.101825

74. Yang J, Zheng Y, Gou X, et al. Prevalence of comorbidities and its effects in patients infected with SARS-CoV-2: a systematic review and meta-analysis. Int J Infect Dis. 2020;94:91-95. doi:10.1016/j.ijid.2020.03.017

75. Salehi S, Abedi A, Balakrishnan S, Gholamrezanezhad A. Coronavirus Disease 2019 (COVID-19): A Systematic Review of Imaging Findings in 919 Patients. AJR Am J Roentgenol. 2020;215(1):87-93. doi:10.2214/AJR.20.23034

76. Klok FA, Kruip MJHA, van der Meer NJM, et al. Incidence of thrombotic complications in critically ill ICU patients with COVID-19. Thromb Res. 2020;191:145-147. doi:10.1016/j.thromres.2020.04.013

77. Ahmed S, Zimba O, Gasparyan AY. Thrombosis in Coronavirus disease 2019 (COVID-19) through the prism of Virchow's triad. Clin Rheumatol. 2020;39(9):2529-2543. doi:10.1007/s10067-020-05275-1

78. Huang J-F, Zheng KI, George J, et al. Fatal outcome in a liver transplant recipient with COVID-19. American Journal of Transplantation. 2020;20(7):1907-1910. doi:https://doi.org/10.1111/ajt.15909

79. Wang B, Li R, Lu Z, Huang Y. Does comorbidity increase the risk of patients with COVID-19: evidence from meta-analysis. Aging (Albany NY). 2020;12(7):6049-6057. doi:10.18632/aging.103000

80. Kumar RN, Tanna SD, Shetty AA, Stosor V. COVID-19 in an HIV-positive kidney transplant recipient. Transp/ Infect Dis. Published online May 26, 2020:e13338. doi:10.1111/tid.13338

81. Columbia University Kidney Transplant Program. Early Description of Coronavirus 2019 Disease in Kidney Transplant Recipients in New York. J Am Soc Nephrol. 2020;31(6):1150-1156. doi:10.1681/ASN.2020030375

82. Chen S, Yin Q, Shi H, et al. A familial cluster, including a kidney transplant recipient, of Coronavirus Disease 2019 (COVID-19) in Wuhan, China. Am J Transplant. 2020;20(7):1869-1874. doi:10.1111/ajt.15903

\section{Figures}




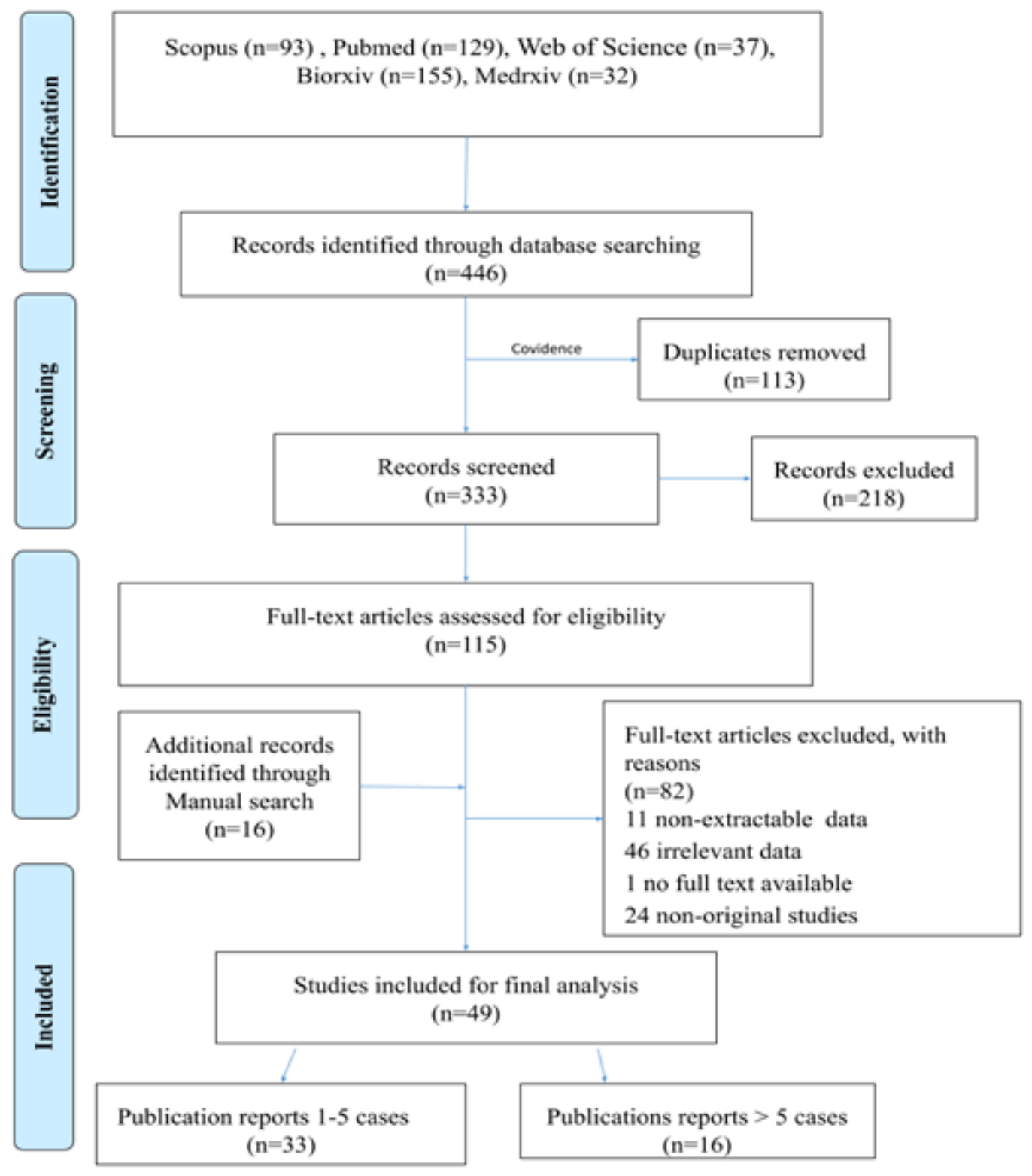

Figure 1

PRISMA flow diagram of study screening and selection. 


\section{Signs and Symptoms}

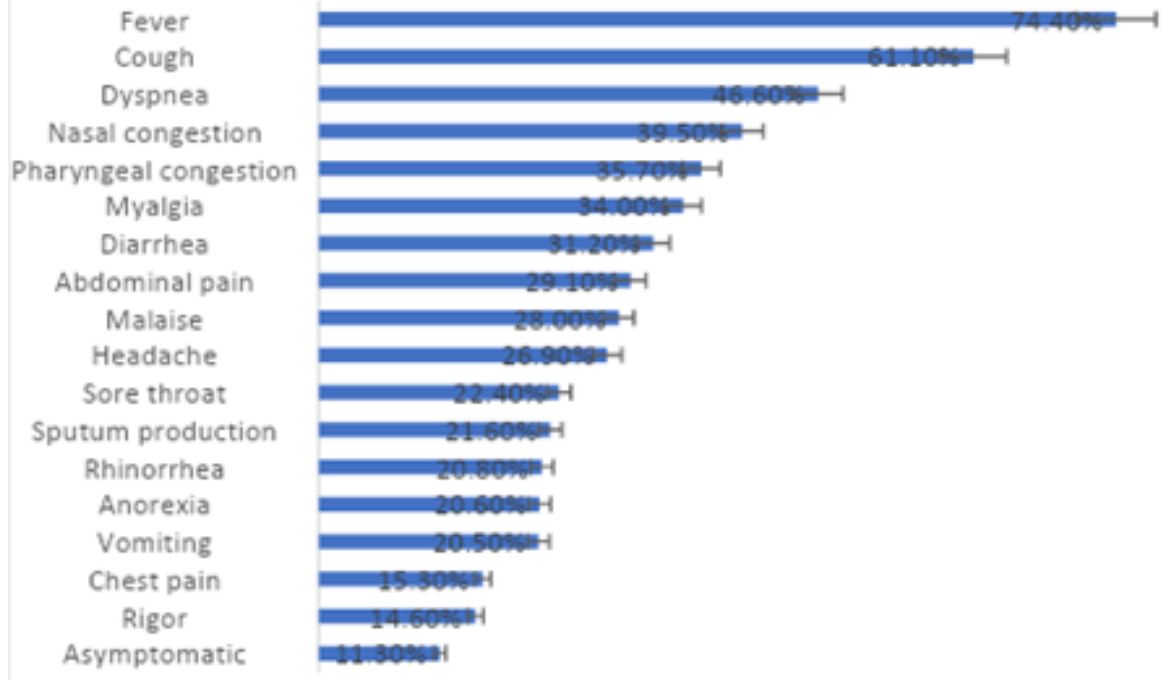

$0.00 \% \quad 10.00 \% \quad 20.00 \% \quad 30.00 \% \quad 40.00 \% \quad 50.00 \% \quad 60.00 \% \quad 70.00 \% \quad 80.00 \% \quad 90.00 \%$

\section{Figure 2}

Event rates for signs and symptoms.

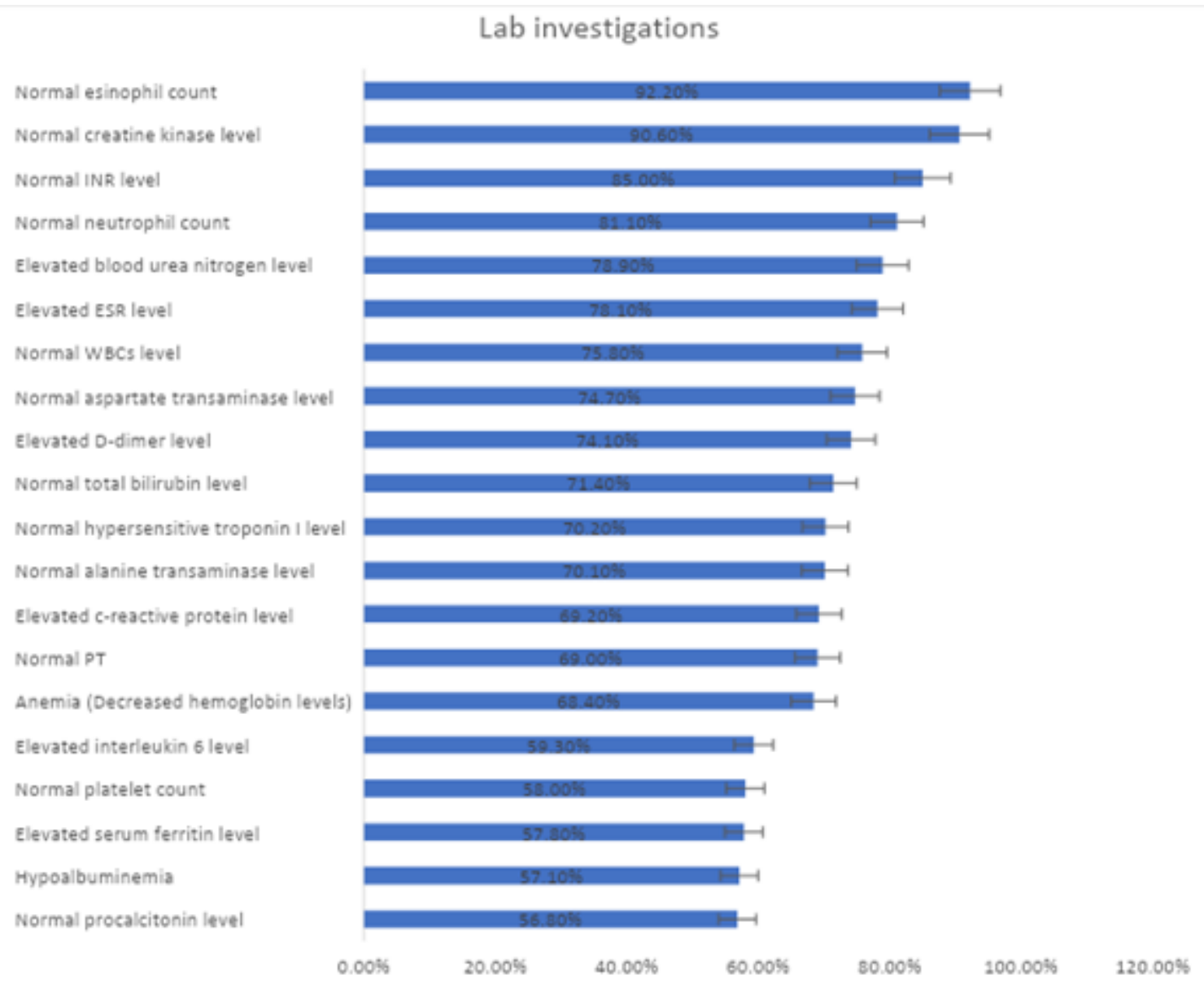

Figure 3

Lab investigation in transplant patients. 
Imaging

Ground glass opacities

Consolidation

Patchy shadows

Dilated small vessels

Interlobular septal thickening

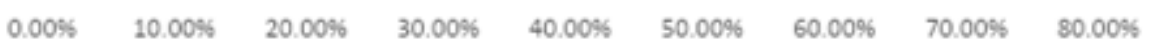

\section{Figure 4}

Event rates of image features in transplant patients.

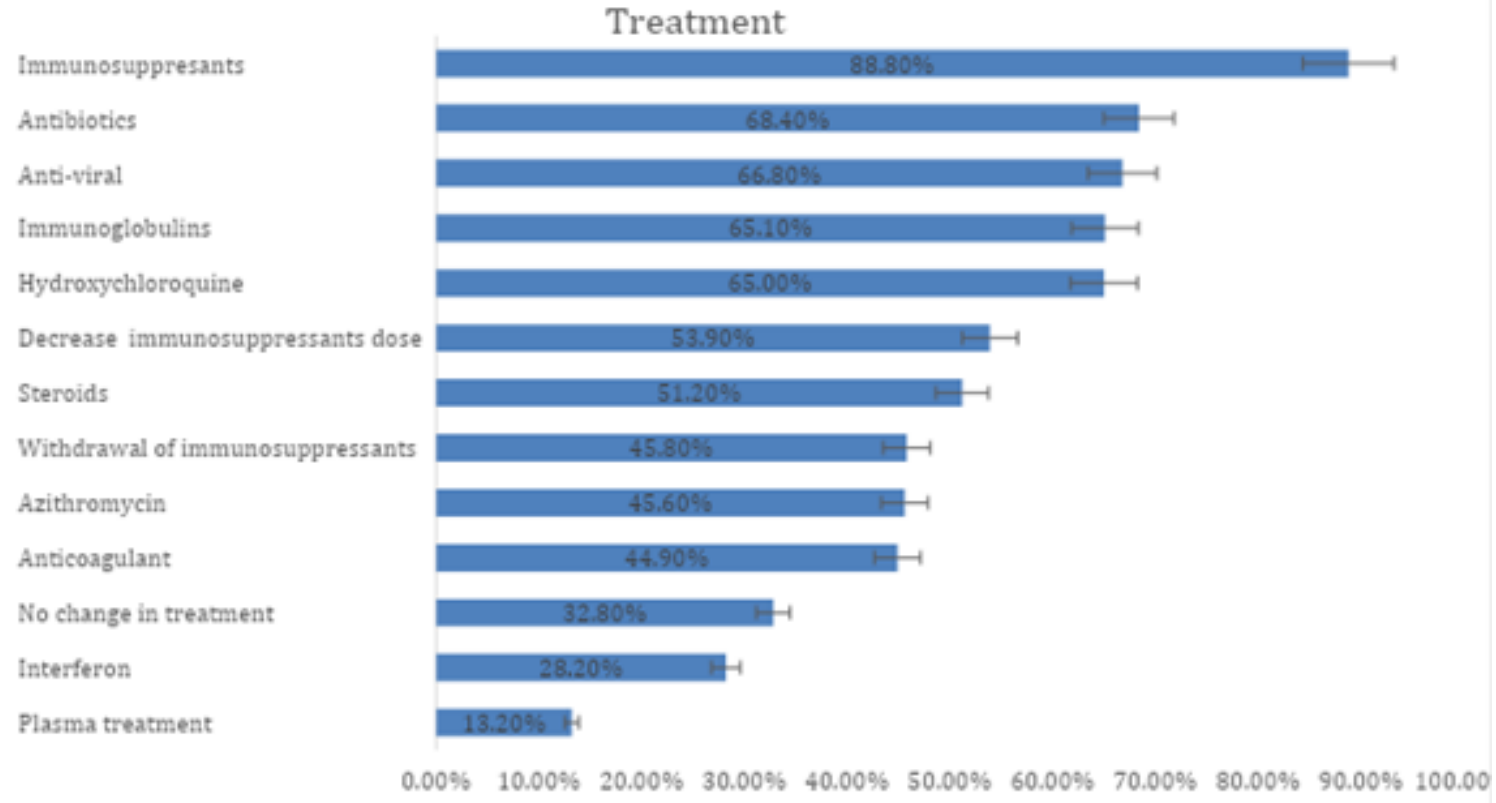

Figure 5

Event rates of treatments used in transplant patients.

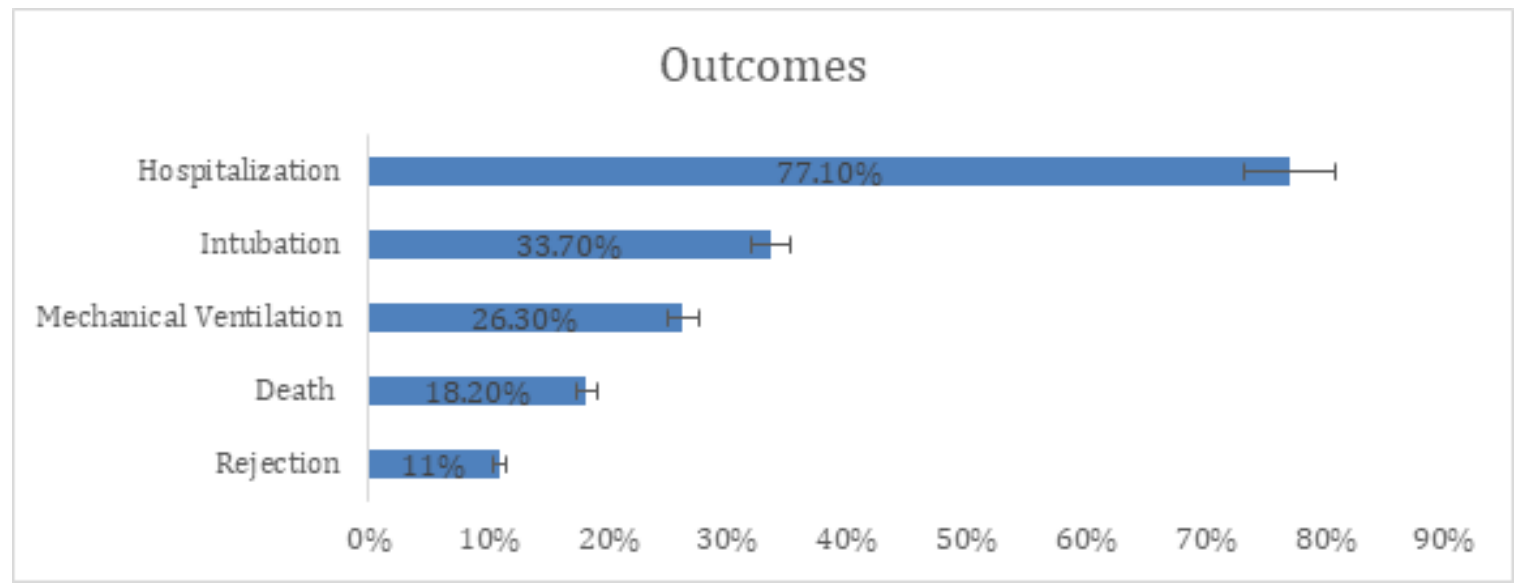

Figure 6 
Clinical outcomes in transplant patients.

\section{Supplementary Files}

This is a list of supplementary files associated with this preprint. Click to download.

- SupplementaryTablesTransplantPaper.docx 